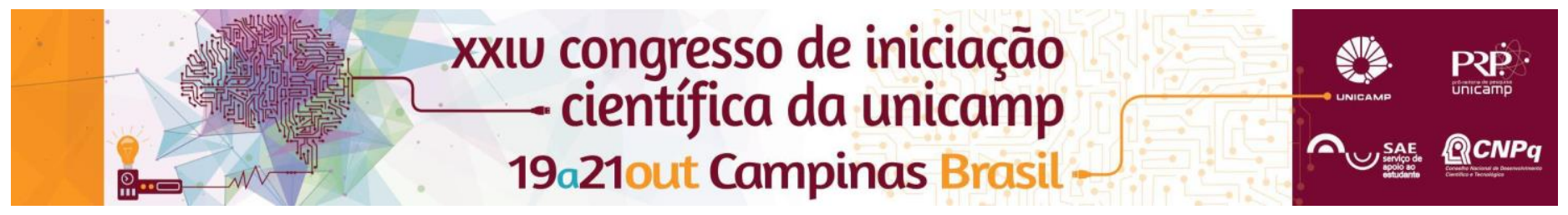

\title{
Caracterização microestrutural de compósitos Al(c.p.)/Si manufaturados pela metalurgia do pó para aplicação aeronáutica.
}

\author{
Rayane Renie Siqueira Santos*, Erik Poloni.
}

\section{Resumo}

A pesquisa realizada neste trabalho tem o objetivo de analisar a microestrutura de compósitos de $\mathrm{Al}(\mathrm{c} . \mathrm{p}$.)/Si manufaturados utilizando-se da metalurgia do pó, com diferentes concentrações de silício (5, 10 e $20 \%$ em massa) mantendo-se a pressão de compactação para as amostras em $1200 \mathrm{MPa}$ e as sinterizações das amostras foram feitas em duas diferentes temperaturas, sendo de $570^{\circ} \mathrm{C}$ e $640^{\circ} \mathrm{C}$.

\section{Palavras-chave:}

Metalurgia do Pó, Alumínio, Sinterização.

\section{Introdução}

As ligas de alumínio são amplamente utilizadas nas diversas indústrias devido às características do alumínio como sua leveza, durabilidade, maleabilidade entre outras propriedades que combinadas com outro elemento podem potencializar as características desejadas [1].

O presente trabalho trata de compósitos metalmetal, i.e. $\mathrm{Al} / \mathrm{Si}$, com potencial aplicação na indústria aeronáutica e aeroespacial, em decorrência da menor massa específica quando comparadas a outros materiais metálicos. Apresentam ainda propriedades melhoradas de resistência à corrosão, fadiga e módulo de elasticidade e menor custo relativo. [2-3].

\section{Resultados e Discussão}

Inicialmente foram produzidas seis amostras que foram compactadas a verde com pressão $1200 \mathrm{MPa}$ e sintetizadas, como mostra-se na Tabela 1. Foram feitas as medidas de densificação das amostras compactadas e após a sinterização.

Tabela 1: Densificacão das amostras. Fonte: Autores.

\begin{tabular}{|c|c|c|c|c|c|}
\hline & Composição & Dens. Exper. & Dens. Teórica & \%Densifcação & \\
\hline \multirow{2}{*}{ Verde } & \multirow{2}{*}{5} & 2,6529 & 2,6630 & 99,6192 & $640^{\circ} \mathrm{C}$ \\
\hline & & 2,6546 & 2,6630 & 99,6831 & $570^{\circ} \mathrm{C}$ \\
\hline \multirow{2}{*}{ Sinterizada } & \multirow[b]{2}{*}{5} & 2,6618 & 2,6630 & 99,9540 & $640^{\circ} \mathrm{C}$ \\
\hline & & 2,5056 & 2,6630 & 94,0879 & $570^{\circ} \mathrm{C}$ \\
\hline \multirow{2}{*}{ Verde } & \multirow{2}{*}{10} & 2,6489 & 2,6815 & 98,7851 & $640^{\circ} \mathrm{C}$ \\
\hline & & 2,6564 & 2,6815 & 99,0627 & $570^{\circ} \mathrm{C}$ \\
\hline \multirow{2}{*}{ Sinterizada } & \multirow[b]{2}{*}{10} & 2,5151 & 2,6815 & 93,7951 & $640^{\circ} \mathrm{C}$ \\
\hline & & 2,4886 & 2,6815 & 92,8063 & $570^{\circ} \mathrm{C}$ \\
\hline \multirow{2}{*}{ Verde } & \multirow{2}{*}{20} & 2,6106 & 2,6260 & 99,4127 & $640^{\circ} \mathrm{C}$ \\
\hline & & 2,6073 & 2,6260 & 99,2860 & $570^{\circ} \mathrm{C}$ \\
\hline \multirow{2}{*}{ Sinterizada } & \multirow[b]{2}{*}{20} & 2,6088 & 2,6260 & 99,3444 & $640^{\circ} \mathrm{C}$ \\
\hline & & 25412 & 26260 & 967723 & $570^{\circ} \mathrm{C}$ \\
\hline
\end{tabular}

Observa-se na Tabela 1 que quanto maior a temperatura de sinterização, maior é a densificação das amostras. Foi possível também analisar os resultados de difração por raio $x$ das amostras compactadas e após a sinterização. Percebendo que não houve o surgimento de uma nova fase em nenhuma das amostras, conforme mostra-se na Fig. 1.
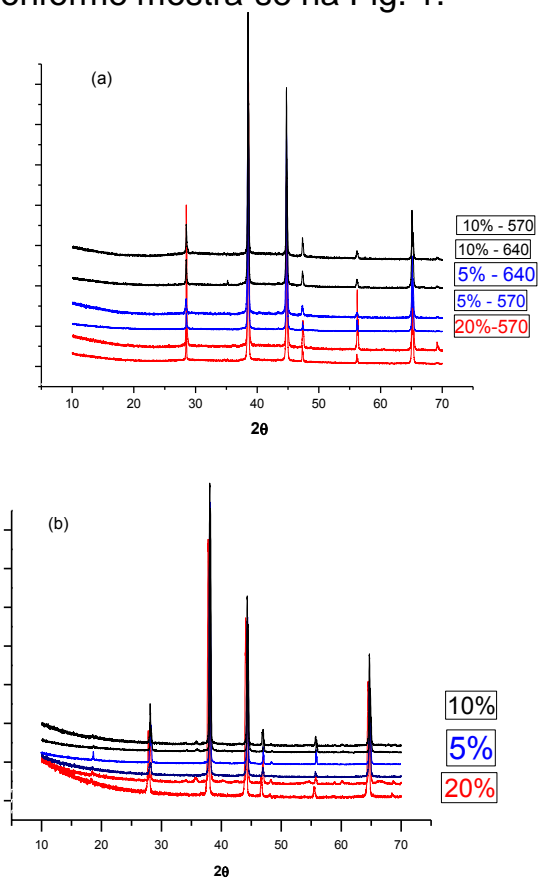

Fig. 1: Difratogramas de Raio $x$ das amostras : (a) sinterizadas em 570 e $640^{\circ} \mathrm{C}$ e (b) comparando-se os diferentes teores de silício. Fonte: Autores.

\section{Conclusões}

Pretende-se ainda analisar as imagens geradas através do MEV, e assim analises mais aprofundadas serão feitas no relatório final.

\section{Agradecimentos}

Agradeço especialmente meu orientador Wislei Riuper Osório pela oportunidade e incentivo e inspiração, agradeço ao Erik Poloni, Rodrigo Bonatti, Diego Costa e Luiz A. Garcia pelo suporte dado na utilização dos laboratórios.

[1] ABAL Associação Brasileira do Alumínio. Acessado em: http://www.abal.org.br/aluminio/vantagens-do-aluminio/

[2] LAGENBECK S L, Sakata I. F., Ekvall J. C., Reinan R. A., Design considerations of new materials for aerospace vehicles. In Aluminium-lithium alloys: design, development and applications update, (eds) R.J. Kar, S. P. Agrawal, W. E. Quist (Metals Park, OH Am. Soc. Metals Int.) pp 293-314, 1987. 